\title{
Parada e Reanimação Cardiopulmonar em Criança: atuação da equipe de enfermagem da Unidade de Terapia Intensiva Pediátrica em hospital público de Vitória da Conquista - Bahia
}

\author{
Elenito Bitencorth Santos ${ }^{1}$
}

\begin{abstract}
Resumo: Objetivo: avaliar o conhecimento da equipe de enfermagem em relação à técnica de Reanimação Cardiopulmonar e medicações utilizadas em crianças internadas na Unidade de Terapia Intensiva Pediátrica do Hospital Geral de Vitória da Conquista, Bahia. Métodos: quanto à natureza a pesquisa é quantitativa descritiva com paradigma positivista, sendo, quanto aos procedimentos técnicos uma pesquisa de campo participante, visando alcançar os objetivos propostos através de estatísticas obtidas pelos questionários. Resultados: os dados estabeleceram o perfil da população estudada; identificação da Parada Cardiopulmonar; os conhecimentos técnicocientíficos dos profissionais: manobras e uso de medicações relevantes na parada cardiorrespiratória; a periodicidade dos treinamentos de Reanimação Cardiopulmonar, onde, dos 25 profissionais de enfermagem da Unidade de Terapia Intensiva Pediátrica, 20\% foram treinados após a admissão e 36\% não receberam treinamento, tendo que aprender o serviço no cotidiano ao exercer suas funções. A equipe pesquisada consegue perceber com êxito a insuficiência respiratória no menor, porém, ao tentar identificar uma parada cardiopulmonar não conseguiram demonstrar seu conhecimento técnico-científico satisfatoriamente, pois revelam respostas incompletas relacionadas a todos os sinais e sintomas do seu início. Um ponto importante a ser trabalhado nos funcionários em questão seria o uso das drogas, direcionando para causa/efeito no organismo da criança com parada cardiorrespiratória. Conclusão: a metodologia utilizada permitiu conhecer a dificuldade enfrentada pela equipe de enfermagem no seu setor de trabalho devido à quantidade reduzida de treinamento e atualização adequada. Um ponto importante a ser trabalhado nos funcionários em questão seria o uso das drogas, direcionando para causa/efeito no organismo da criança com parada cardiorrespiratória.
\end{abstract}

Palavras-chave: Atuação. Enfermagem. Parada. Reanimação cardiorrespiratória. Criança.

\section{Cardiopulmonary arrest and resuscitation in children: Performance of the Nursing staff of the Intensive Pedriatic Care Unit in a public hospital in Vitoria da Conquista in Bahia}

\begin{abstract}
Objective: to evaluate the knowledge of the nursing staff regarding the technique of Cardiopulmonary Resuscitation and medications used in children admitted to the Pediatric Intensive Care Unit of the General Hospital of Vitória da Conquista in Bahia. Methods: the research is quantitative descriptive with positivist paradigm, being, as far as the technical procedures, a participatory field research, aiming to reach the proposed objectives through statistics obtained by the questionnaires. Results: the data established the profile of the population studied; identification of cardiopulmonary arrest; the technical-scientific knowledge of the professionals: maneuvers and use of medications relevant to cardiorespiratory arrest; the periodicity of the Cardiopulmonary Resuscitation training, where $20 \%$ of the 25 nursing professionals of the Pediatric Intensive Care Unit were trained after admission and $36 \%$ did not receive training, having to learn the daily routine while performing their duties. The researched team can successfully understand the respiratory failure in the minor, but in trying to identify a cardiopulmonary arrest they failed to demonstrate their technical-scientific knowledge

\footnotetext{
${ }^{1}$ Mestre em Teologia pela Faculdades EST (EST, São Leopoldo/RS, Brasil). Disponível em: <http://www.est.edu.br/>. Enfermeiro especialista em Urgência e Emergência e em Hematologia, Hemoterapia e Terapia de Suporte. Pós-graduado em MBA Executivo em Gestão Hospitalar e Cuidados Paliativos. Funcionário Público da UTI Pediátrica de Vitória da Conquista/Ba. Professor da Educação profissional - Secretaria da Educação / Governo do Estado da Bahia.
}

E-mail: ebs_2011@hotmail.com
\end{abstract}


satisfactorily, as they reveal incomplete responses related to all the signs and symptoms of its onset. An important point to be worked on by the employees in question would be the use of drugs, directing to cause / effect in the body of the child with cardiorespiratory arrest. Conclusion: the methodology that was used allowed to know the difficulty faced by the nursing team in their work sector due to the reduced amount of training and adequate updating. An important point to be worked on by the employees in question would be the use of drugs, directing to cause / effect in the body of the child with cardiorespiratory arrest.

Keywords: Performance. Nursing. Cardiac Arrest. Cardiorespiratory resuscitation. Child.

\section{Introdução}

Com base bibliográfica, sabe-se que, "a Terapia Intensiva Pediátrica surgiu nos Estados Unidos da América (EUA) no final dos anos 60. No Brasil, os primeiros Centros de Terapia Intensiva Pediátrica (CTIP) surgiram na década de 70". ${ }^{2}$

Apesar de ofertar cuidados especializados e diferenciados, a mortalidade só foi impactada, após atingir grandes avanços tecnológicos e o melhor aperfeiçoamento do conhecimento técnico da equipe multiprofissional a partir da década de 90. Mas, para que se possa admitir um paciente na terapia intensiva pediátrica é preciso seguir critérios que estão intimamente relacionados com o tema proposto para a pesquisa científica que será posteriormente estudada. Esse internamento será feito por triagem médica de pacientes agudos graves ou sem doença de base agudizada, instáveis, com disfunção de um ou mais órgãos, que necessitem de suporte ventilatório, cardiocirculatório (medicamentos vasoativos), neurológico, metabólico ou de métodos dialíticos. ${ }^{3}$

Devido a essas complicações, têm-se observado a Parada Cardiopulmonar em crianças no momento do internamento (admissão), ou no decorrer de sua estadia na UTIP, ${ }^{4}$ o qual exige da equipe multiprofissional:

"Competência, habilidade e destreza; disponibilidade para cuidar de clientes críticos; preparação para luta diária com a vida e com a morte; preparação para adaptar-se aos ruídos dos aparelhos; conhecimento técnico e científico".5

No entanto, tal competência, habilidade e destreza adquiridas por profissionais de saúde são consequências de um bom treinamento, perene e ininterrupto com disposição para a

\footnotetext{
${ }^{2}$ STAPE et al., 2009, p.1

${ }^{3}$ STAPE et. al., 2009, p.1-2

${ }^{4}$ UTIP: Unidade de Terapia Intensiva Pediátrica

${ }^{5}$ FIGUEIREDO, SILVA, SILVA, 2009, p.3 
aprendizagem das técnicas científicas que envolvem a parada e reanimação cardiopulmonar em crianças, possibilitando assim, ao profissional, o agir imediato quando os sinais e sintomas da PCR são perceptíveis em decorrência do alto nível de conhecimento. O que significa dizer que: “A parada cardiorrespiratória é uma situação caracterizada por inconsciência, com ausência de resposta a estímulos, apnéia e ausência de pulsos palpáveis". ${ }^{6}$

“A $\mathrm{PCR}^{7}$ é a cessação abrupta das funções cardíacas, respiratória e cerebral, podendo ser comprovada pela ausência do pulso central (carotídeo ou femoral), de movimentos respiratórios (apnéia), além do estado de consciência alterado". ${ }^{8}$

Com base no levantamento destes dados, surgiu um questionamento, impulsionando assim, a realização de um estudo de pesquisa, sendo ele: "Qual seria a conduta inicial da equipe de enfermagem (técnicos e enfermeiros), frente a uma Parada Cardiorrespiratória (PCR) na UTIP do Hospital Geral de Vitória da Conquista (HGVC)?” Indagação essa, que levou um delineamento de um tema proposto: Parada e Reanimação Cardiorrespiratória em Crianças: atuação da equipe de enfermagem da UTIP em hospital estadual de Vitória da Conquista - BA.

Com a vivência diária em uma UTIP na assistência a crianças em estado crítico, percebese que:

Uma reanimação cardiopulmonar com técnicas corretas consegue um sucesso inicial (...), em dois terços das crianças reanimadas. Dessas, um terço estarão vivas 24 horas depois, mas apenas $15-20 \%$ das crianças que tiveram uma parada cardíaca em ambiente hospitalar, estarão vivas em um ano depois do evento. Desses sobreviventes, a maioria apresentará seqüelas significativas. ${ }^{9}$

Esses resultados frustrantes ajudam-nos a entender que é sempre muito mais importante identificar os pacientes sob risco de uma parada cardíaca do que ter que reanimar uma criança. ${ }^{10}$

Com essa justificativa, faz-se necessário, estipular o objetivo geral que é: “Avaliar o conhecimento da equipe de enfermagem em relação à técnica de RCP e medicações utilizadas em crianças internadas na UTIP do HGVC." Seguindo essa linha de pensamento, serão utilizados os objetivos específicos que irar: identificar os métodos realizados dentro da UTIP para constatar o início da PCR; examinar o conhecimento técnico-científico a respeito do cuidado intensivo pediátrico no momento da PCR (manobras e quais as medicações mais usadas

\footnotetext{
${ }^{6}$ OLIVEIRA, 2005, p.223

${ }^{7}$ PCR: Parada Cardiopulmonar

${ }^{8}$ GRASSIA, 2007, p.495

${ }^{9}$ OLIVEIRA, 2005, p. 223

${ }^{10}$ OLIVEIRA, 2005, p.223 
na parada); investigar a periodicidade dos treinamentos de RCP, uso e efeito das medicações administradas.

O estudo testará as seguintes hipóteses:

- A identificação dos sinais e sintomas de uma PCR é primeiramente evidenciada pelos profissionais de enfermagem, fato esse, associado à proximidade da categoria ao paciente da UTIP.

- O stress da equipe de enfermagem está relacionado ao confinamento na unidade e a longas jornadas de trabalho, dificultando assim, o relacionamento interpessoal e a ineficácia do exercício profissional diante de uma PCR.

- A administração mecânica das medicações, sem o devido conhecimento de causa/efeito sobre o paciente, e a falta de treinamento regular das manobras de RCP tem tornado os profissionais inseguros (com medo do desconhecido) para a atuação com prazer, eficiência e eficácia das atividades relacionadas à ressuscitação em crianças.

\section{Antecedentes Históricos: Parada e Reanimação Cardiorrespiratória em Crianças - Atuação da enfermagem:}

Alguns Historiadores bíblicos chegaram a relatar a primeira ressuscitação com registro na Bíblia, onde, o profeta Eliseu reanimou o filho da mulher Sunamita. ${ }^{11}$

Outro fato histórico revela que:

Em 1930, Paracelsus, usou foles de lareira para insuflar os pulmões de indivíduos aparentemente mortos. Muitas técnicas e rituais foram desenvolvidos com o objetivo de insuflar os pulmões, entre os séculos XVII e XX na tentativa de socorrer o paciente com evidências de PCP. (...) A preconização da massagem cardíaca e da respiração boca-a-boca foi realizada pela primeira vez, em 1817, por Massius; sendo que a primeira desfibrilação no homem foi realizada por Beck, em 1947. Esses métodos têm sido ao longo dos anos, aperfeiçoados e divulgados para uso não só profissional, mas social. $^{12}$

Está provado cientificamente que antes da PCR a criança apresenta alguns sinais relevantes que ajudará o profissional de enfermagem a identificar e evitar este evento, pois a parada súbita em criança é rara; com isso, percebe-se que:

\footnotetext{
${ }^{11}$ II REIS 4:34

${ }^{12}$ PAVELQUEIRES, S. et al. 2006, p.242 
A parada cardiorrespiratória (PCR) em criança, na maioria das vezes, é o resultado final da deterioração da função respiratória ou choque que leva a hipoxemia e à acidose progressiva, com parada cardíaca secundária. Conseqüentemente, o ritmo cardíaco, terminal mais comum, é a bradicardia com progressão para assistolia. A Parada cardíaca primária súbita é evento raro em pediatria. Essa condição é mais freqüentemente encontrada em adultos e é provocada pelo desenvolvimento de arritmias, fibrilação ventricular e taquicardia ventricular. ${ }^{13}$

“A assistolia o principal distúrbio do ritmo cardíaco causador da interrupção na circulação sanguínea, podendo seu aparecimento ser conseqüência da falência respiratória (parada respiratória) e/ou circulatória (choque)". ${ }^{14}$

Em decorrência da explanação dos assuntos citados acima, percebe-se um alto grau de responsabilidade na equipe de enfermagem ao perceber uma PCR em criança, tendo que agir com destreza, raciocínio clínico rápido, objetivo e claro, demonstrando sincronia e sinergismo com os outros membros da equipe, ter maturidade, equilíbrio emocional, flexibilidade e capacidade de adaptação aos eventos presenciados. Relatos descrevem que:

$\mathrm{O}$ índice de sobrevida de pessoas submetidas à reanimação cardiopulmonar e cerebral (RCP) eleva-se acentuadamente, quando o suporte básico de vida (SBV ou BLS Basic Life Support) é iniciado nos primeiros quatro minutos e o suporte avançado de vida (SAV ou ACLS - Advanced Cardiac Life Support), em até oito minutos, o cérebro começa a sofrer danos e, em 10, a morte cerebral esta confirmada. ${ }^{15}$

Para se diagnosticar a parada cardíaca é necessária à percepção do débito cardíaco ausente ou inefetivo que resulta em ausência de pulsos em grandes artérias que se obtém pela palpação. O mesmo autor, também descreve que:

A circulação artificial é realizada por meio da compressão torácica que deve ser indicada na ausência do pulso central ou na bradicardia ( $\mathrm{FC}<60 / \mathrm{min}$ ) com hipoperfusão. A técnica para fazer a compressão torácica varia com a idade da criança, e devem ser seriadas, rítmicas, vigorosas e com mínimos de interrupções: A técnica no lactente $(<1$ ano) é a de envolvimento do tórax com a colocação dos polegares imediatamente abaixo da linha dos mamilos. Uma alternativa é a utilização de dois dedos sobre o esterno para fazer a compressão. Nas crianças de 1 a 8 anos, o local de compressão também é na região do esterno entre os mamilos. É realizada com a região tenar ou hipotenar de uma das mãos do socorrista, sem colocar os dedos sobre as costelas. Essa técnica exige que a criança esteja sobre uma superfície firme; o socorrista deve estar situado bem acima da criança, mantendo os braços dela esticados durante a compressão. Nas crianças maiores de 8 anos é recomendada técnica

\footnotetext{
${ }^{13}$ STAPE et. al., 2009, p.21

${ }^{14}$ STOPFKUCHEN, 2010, p.129

${ }^{15}$ KROSGER, et al., 2010, p.204 
semelhante às descritas para adultos, em que o socorrista posiciona uma mão sobre a outra para fazer a compressão. ${ }^{16}$

“A classificação do menor, considera-se relevante no atendimento a PCR, sendo feita por idade de neonato (até 28 dias), bebês ( $<1$ ano) e crianças (de 1 ano até a puberdade)". ${ }^{17}$

Evidencia-se nas pesquisas em enfermagem uma preocupação dos enfermeiros em uniformizar a linguagem pela construção de uma classificação única de enfermagem (...) classificar significa uma linguagem que possa descrever os julgamentos clínicos pelos quais os enfermeiros são responsáveis. Segundo Gordon (1998), já na Bíblia existe alusões às classificações, no livro de Gênesis (...). ${ }^{18}$

Na realização das manobras em crianças são prudentes os profissionais que utilizam a classificação por idade e ao mesmo tempo, algumas técnicas para uma boa eficácia no procedimento realizado, onde, na manutenção das vias aéreas pérveas e na respiração em bebês, deve-se, inclinar a cabeça (chin lift) e elevar o mento (jaw thrust), em caso de trauma não inclinar a cabeça, devem receber duas ventilações por 1 segundo (cada ventilação), mantendo um padrão de 12-20 ipm na ausência de pulso. Após a via aérea avançada, manter a ventilação de 6-10 ipm. ${ }^{19}$

O mesmo autor referenciado acima diz que em crianças deve-se inclinar a cabeça e elevar o mento (se há trauma, use somente a elevação da mandíbula), onde serão ofertadas duas ventilações por 1 segundo cada ventilação, mantendo um padrão de 10-12 ipm na ausência de pulso. Após a via aérea avançada manter a velocidade de 8-10 ipm. Ao se tratar da pesquisa de sinais da circulação, área, posicionamento das mãos e profundidade das compressões em bebês serão analisados os pulsos: Braquial e femoral, na ausência, envolver o tórax do bebê com as mãos e pressionar o esterno, imediatamente abaixo da linha mamilar com 2 dedos, com profundidade de 1,5 a 2,5 cm. Já em crianças os pulsos aferidos serão: Carotídeo e femoral, na ausência, com os braços eretos a $90^{\circ}$, posicionar a região hipotenar de uma das mãos sobre o esterno da criança envolvida pela outra mão, comprimindo a uma profundidade de 2,5 a 3,5 cm, com uma seleção de compressão/ventilação de 30:2 (um profissional) e 15:2 (dois profissionais)..$^{20}$

\footnotetext{
${ }^{16}$ STAPE, et. al., 2009, p.24-25

${ }^{17}$ PAVELQUEIRES, S. et. al. 2006, p.200

${ }^{18}$ CHIACA, 2008 apud Tannure e Pinheiro, 2010, p.207

${ }^{19}$ PAVELQUEIRES, S. et. al. 2006, p.209

${ }^{20}$ PAVELQUEIRES, S. et. al. 2006, p.209 
No bebê a relação entre a compressão e ventilação é a mesma que em crianças. O DEA (desfibrilador elétrico automático) está indicado após cinco ciclos de RCP em caso de parada não presenciada e precocemente em caso de colapso súbito presenciado. As pás devem ser adequadas para o tamanho da vítima. A carga elétrica inicial é de $2 \mathrm{~J} / \mathrm{kg}$ e de $4 \mathrm{~J} / \mathrm{kg}$ a partir do segundo choque. ${ }^{21}$

A indicação para a utilização do desfibrilador elétrico é nítido ao percebermos que:

A desfibrilação é a despolarização assíncrona de uma massa crítica de células miocárdicas e esta indicada nos casos de parada cardíaca em que há risco de colapso e fibrilação ventricular ou taquicardia ventricular sem pulso. A desfibrilação não é efetiva na assistolia, na atividade elétrica sem pulso e na bradicardia. ${ }^{22}$

Tannure e Pinheiro chegam à conclusão de que "a realização de um plano individualizado é uma ferramenta eficiente que facilita a identificação de situações de riscos e contribuição para a qualidade e melhoria dos cuidados prestados". ${ }^{23}$

\section{Farmacoterapia - As medicações mais usadas na PCR:}

“As medicações mais usadas na PCR são: Epinefrina; Bicarbonato de Sódio; Cálcio; Magnésio; Glicose; Atropina; Vasopressina; Amiodarona e Lidocaína.” Sendo que a:

\footnotetext{
Epinefrina: trata-se de catecolamina endógena com ação estimulante nos receptores $\alpha$ e $\beta$; a ação $\alpha$ é a mais importante durante a parada cardíaca por causar vasoconstrição e restaurar a pressão diastólica da aorta, proporcionando assim melhor perfusão miocárdica e cerebral. Deve ser administrado tão logo seja obtido acesso vascular, e deve ser repetida a cada 3 a 5 min durante a RCP.

Bicarbonato de sódio: A prioridade no tratamento da acidose metabólica que ocorre na criança em PCR deve ser a ventilação assistida, a suplementação de oxigênio e a restauração da perfusão por meio das compressões torácica e do uso de epinefrina.

Cálcio: é preconizado quando houver suspeita ou comprovação de hipocalcemia, hiperpotassemia, hipermagnesemia e superdosagem de bloqueadores de canais de cálcio.

Magnésio: a ação do magnésio na hipomagnesemia e torsades de pointes (arritmia relacionada à parada cardíaca) foi confirmada por estudos clínicos.

Glicose: a hipoglicemia pode ocorrer durante episódios de falência cardiorrespiratória nos lactentes jovens e em crianças com doenças crônicas, além disso, como a glicose é o principal substrato para o miocárdio do $\mathrm{RN}$, a hipoglicemia pode levar a grave disfunção cardíaca.
}

\footnotetext{
${ }^{21}$ PAVELQUEIRES, S. et. al. 2006, p.209

${ }^{22}$ STAPE, et. al., 2009, p.31

${ }^{23}$ TANNURE, M. C.; PINHEIRO, A. M., 2010, p.220 
Atropina: é um fármaco parassimpaticolítico que acelera a condução no nó sinoatrial e atrioventricular. Atropina é recomendada no tratamento de bradicardia sintomática causada por bloqueio AV ou aumento da atividade vagal como, por exemplo, durante a intubação.

Vasopressina: é um hormônio que atuam em receptores específicos que causam vasoconstrição sistêmica (...) e reabsorção de água no túbulo renal (...). A vasopressina produz aumento dos fluxos sanguíneos cardíaco e cerebral em modelos experimentais de parada cardíaca, e, em adultos, a administração de epinefrina mais vasopressina foi associada com maior sobrevida pós-PCR. Entretanto não há dados para avaliar sua eficácia e segurança em crianças e lactentes até o momento.

Amiodarona: é um antiarrítmico lipossolúvel inibidor não-competitivo de receptores alfa e beta-adrenérgicos. É efetiva no tratamento de fibrilação e taquicardia ventricular em adultos e crianças (...).

Lidocaína: é um bloqueador do canal de sódio que suprime arritmias ventriculares (...). Lidocaína pode ser considerada em crianças com FV ou TV sem pulso resistente ao choque elétrico. ${ }^{24}$

Diante do exposto acima, percebe-se que para uma melhor reabilitação e sobrevida da criança em PCR, os profissionais de saúde devem ter um conhecimento mais acurado na farmacoterapia do menor em parada cardiopulmonar, onde, faz-se necessário observar o uso correto das vias de acesso para a infusão das medicações, tais como: vias periféricas, acesso intraósseo, tubo orotraqueal, veia central e veia umbilical.

\section{O estresse da equipe de enfermagem na Unidade de Terapia Intensiva Pediátrica:}

Com base em um estudo descritivo realizado por Coronetti que teve como objetivo a investigação do estresse vivenciado pela equipe de enfermagem que atua em Unidade de Terapia Intensiva, o autor, obteve alguns resultados que possibilitaram a identificação dos fatores estressantes, como também, sua manifestação na equipe, tendo o enfermeiro que lidar com essa situação, minimizando ou prevenindo o estresse na UTI. O artigo aponta o stress como sendo um fator negativo que ocasiona prejuízos no desempenho global do indivíduo, seja, no âmbito profissional, social ou ambiental. ${ }^{25}$

A UTI como é um ambiente físico com iluminação e ventilação inadequadas, com barulho excessivo, e que, diversas vezes existe escassez de recursos materiais, também é um local de trabalho fechado que há um contato maior entre os profissionais, um relacionamento, onde, querendo ou não dependem um do outro para melhorar a qualidade da assistência ao

\footnotetext{
${ }^{24}$ STAPE, et. al., 2009, p.27-31

${ }^{25}$ CORONETTI, et. al., 2006 
paciente crítico, contudo, sabe-se que, uma relação forçada pode desencadear uma comunicação deficiente e privilegiada, trazendo a falta de cooperação, levando a equipe a uma sobrecarga de tarefas no trabalho, tornando o profissional de enfermagem mais lento nas ações emergenciais dentro da UTI, devido ao cansaço. Foram apontadas como principal causa de estresse o relacionamento interpessoal e a falta de recursos humanos e materiais, levando as seguintes sugestões: melhorar as condições de trabalho, em busca da qualidade de vida, proporcionando mais cooperação dos membros nas atividades, maior participação do enfermeiro no cuidado e nas orientações aos funcionários, distribuir justamente as atividades, respeitando os profissionais, desenvolver um serviço de apoio psicológico. ${ }^{26}$

"Os profissionais que trabalham em UTIP e neonatal, pela especificidade do seu trabalho, estão expostos ao risco do estresse ocupacional (...). Estes dados sugerem a necessidade de serem feitas pesquisas, com o objetivo de desenvolver medidas preventivas e modelos de intervenção.",27

Com base nessa problemática, fez-se necessário especular os fatores de risco para desencadeamento do stress dentro de uma Unidade de Terapia Intensiva Pediátrica para tentar melhorar a assistência à criança grave.

\section{Destaques das Diretrizes da American Heart Association 2010 para RCP:}

A American Heart Association de 5 em 5 anos se reúnem para revisar as Diretrizes concernentes a RCP; e neste ano de 2010, envolveu 356 especialistas em ressuscitação em 29 países, que analisaram, discutiram e debateram a pesquisa em ressuscitação em encontros durante 36 meses. Especialistas em planilha produziram 411 revisões de evidências científicas de 277 tópicos em ressuscitação e atendimento cardiovascular de emergência (ACE). Enquanto que, as Diretrizes da AHA de 2005 para RCP, enfatizavam a alta qualidade nas compressões torácicas destacando sua importância (frequência e profundidade adequada, permitindo retorno total do tórax após cada compressão e com interrupções mínimas nas compressões torácicas), mesmo assim, estudos publicados antes e desde 2005, demonstraram que a necessidade de

\footnotetext{
${ }^{26}$ CORONETTI, et. al., 2006

${ }^{27}$ Rev Bras Ter Intensiva. 2008; 20 (3) : 261 
melhorias nas compressões torácicas continua presente. As Diretrizes da AHA de 2010 para RCP tentam dar conta dessas questões, onde a melhoria dos resultados da RCP é primordial. ${ }^{28}$

As Diretrizes da AHA 2010 para RCP enfatizam a necessidade de uma RCP de alta qualidade com ênfase permanente em Reanimação Cardiopulmonar, incluindo: Frequência de compressões mínima de 100/minuto (em vez de "aproximadamente" 100/minuto, como era antes); profundidade de compressão mínima de 2 polegadas $(5 \mathrm{~cm})$, em adultos, e de, no mínimo, um terço do diâmetro anteroposterior do tórax, em bebês e crianças (aproximadamente, 1,5 polegada [4 $\mathrm{cm}]$ em bebês e 2 polegadas [ $5 \mathrm{~cm}]$ em crianças); retorno total do tórax após cada compressão; minimização das interrupções nas compressões torácicas; evitar excesso de ventilação. $^{29}$

\section{Alterações dos principais pontos de discussão das Diretrizes 2010 para RCP}

Conforme as Diretrizes da AHA 2010 para RCP em pediatria, não serão mais realizadas as ventilações de resgate para não retardar as compressões torácicas e minimizar o atraso das ventilações, pois foi constatado que quando o profissional de saúde tem dúvidas quanto a A-BC (via aérea, respiração, compressões torácicas), eles não conseguem fazer nada para socorrer a vítima pediátrica acometida de PCR, mas com a mudança de A-B-C para C-A-B (compressões torácicas, via aérea, respiração), foi adotado com a esperança de aumentar a chance de que pessoas presentes executem a RCP em crianças e bebês, onde, teoricamente, a nova sequência deve retardar as ventilações de resgate em apenas 18 segundos (o tempo necessário para aplicar 30 compressões) ou menos (com 2 socorristas). Segundo alguns dados recentes, compressões torácicas eficazes, exigem a aplicação de força, então, recomenda-se a profundidade de $1 \frac{1}{1} 2$ polegada $(4 \mathrm{~cm})$ para a maioria dos bebês e cerca de 2 polegadas $(5 \mathrm{~cm})$ para a maioria das crianças. Ainda menciona que foi eliminado o procedimento "ver, ouvir e sentir se há respiração" da sequencia da avaliação da respiração após a liberação da via aérea, pois se perdia muito tempo, e outra, não se libera mais a via aérea primeiro, e sim comprime o tórax com força, com rapidez, que no caso será executado só o bebê ou criança não responder as solicitações e não estiver respirando ou apenas em gasping, sendo indicado o início das

\footnotetext{
${ }^{28}$ DIRETRIZES DA AMERICAN HEART ASSOCIATION, 2010 ${ }^{29}$ DIRETRIZES DA AMERICAN HEART ASSOCIATION, 2010 
compressões com a sequencia C-A-B. Os profissionais devem tentar sentir o pulso por 10 segundos (braquial, em bebês, e carotídeo ou femoral, em crianças), se não conseguir, pois na emergência/urgência a detecção do pulso não é muito confiável, será necessário observar, se a criança ou bebê não responde ou não respira ou se encontra em gasping e em seguida pode começar a RCP pelas compressões torácicas, onde, será 30:2 para um socorrista de crianças e bebês; e 15:2 para dois socorristas, tendo que fazer ventilação de resgate em aproximadamente, 1 segundo. Quando houver uma via aérea avançada, as compressões torácicas não podem ser interrompidas para alternar com as ventilações, tem que ser contínuas (a uma frequência mínima de 100/minuto) e uma ventilação a cada 6 a 8 segundos (cerca de 8 a 10 ventilações por minuto), evitando ventilações excessivas. ${ }^{30}$

A respeito do desfibrilador é preferível usar um manual a um DEA/DAE para desfibrilação em pediatria. Se não houver um desfibrilador manual disponível, prefira um DEA/DAE equipado com um atenuador de carga pediátrica. É recomendável o uso de uma carga de 2 a $4 \mathrm{~J} / \mathrm{Kg}$ para desfibrilar; mas pode-se usar uma carga inicial de $2 \mathrm{~J} / \mathrm{Kg}$ e em seguida ir aumentando a carga, com cargas subsequentes de no mínimo, $4 \mathrm{~J} / \mathrm{Kg}$, sendo considerado níveis de energia mais alta desde que não exceda a $10 \mathrm{~J} / \mathrm{Kg}$ ou a carga mínima adulta. ${ }^{31}$

A fim de limitar o risco de hiperoxemia, foi adicionada uma nova recomendação de titular o oxigênio inspirado (quando houver equipamento apropriando disponível), após o retorno da circulação espontânea, manter uma saturação de oxi-hemoglobina $\geq 94 \%$ mas < 100\% (entre 94\% e 99\%). Não se recomenda a administração de rotina do cálcio na PCR pediátrica na ausência de hipocalcemia, overdose documentada de bloqueador dos canais de cálcio, hipermagnesemia ou hipercalemia, sendo que sua administração de rotina nas crianças com PCR não produz benefícios e pode ser nociva. ${ }^{32}$

\section{Metodologia}

O cenário de estudo dessa pesquisa, foi a UTI Pediátrica do Hospital Geral de Vitória da conquista, localizada na Avenida Filipinas, SN, Bairro: Jardim Guanabara, Vitória da

\footnotetext{
${ }^{30}$ DIRETRIZES DA AMERICAN HEART ASSOCIATION, 2010

${ }^{31}$ DIRETRIZES DA AMERICAN HEART ASSOCIATION, 2010

${ }^{32}$ DIRETRIZES DA AMERICAN HEART ASSOCIATION, 2010 
Conquista-Bahia. A equipe da UTI Pediátrica é composta por profissionais do nível técnico e superior, sendo, uma equipe multiprofissional de médicos, enfermeiros, fisioterapeutas e técnicos em enfermagem, mas a categoria de interesse para o estudo será a equipe de enfermagem atuante na Unidade de Terapia Intensiva Pediátrica do HGVC, tendo uma população de 32 funcionários. Equipe essa, escolhida com o intuito de avaliar a atuação da enfermagem frente a um PCR em crianças. Dentre estes, vinte e quatro (24) são técnicos em enfermagem e oito (8) são enfermeiros. Da população, apenas 25 responderam ao questionário.

Este estudo tem como base uma pesquisa quantitativa descritiva com paradigma positivista, tendo, como relevância o estudo da população adscrita na área da enfermagem, sendo quanto aos procedimentos técnicos uma pesquisa de campo participante, visando alcançar os objetivos que foram propostos. O paradigma positivista é:

\footnotetext{
Um pressuposto fundamental do positivismo é que existe uma realidade lá fora que pode ser estudada e conhecida (...). No paradigma positivista, grande parte da atividade do pesquisador científico está direcionada para a compreensão das causas subjacentes dos fenômenos naturais (...). O pressuposto relacionado, do determinismo, refere-se á crenças dos positivistas de que os fenômenos não são eventos casuais ou aleatórios, mas têm causas antecedentes. (...) os positivistas tendem a ser tão objetivos quanto possível em busca do conhecimento. ${ }^{33}$
}

Para analisar a atuação da enfermagem frente a uma PCR em crianças menores de 14 anos, foram distribuídos questionários estruturados para todos os profissionais de enfermagem do serviço da UTI Pediátrica do Hospital Geral de Vitória da Conquista, onde, foram coletadas as informações relacionadas ao perfil do sujeito da pesquisa; às técnicas usadas para detecção de uma PCR; examinar se a enfermagem conhece a causa/efeito das drogas sobre os pacientes com PCR e investigar a periodicidade dos treinamentos em RCP.

Após aplicação do questionário para os profissionais de enfermagem do serviço da UTIP do Hospital Regional de Vitória da Conquista/Ba, foi realizado a tabulação dos dados consolidando e agrupando-os por questões:

- Figura 1 e 2 - foi traçado o perfil do sujeito da pesquisa;

- Figura 3 - identificado se houve treinamento recebido pelos sujeitos da pesquisa em RCP e se eles participaram;

${ }^{33}$ POLIT, D. F.; BECK, C. T.; HUNGLER, B. P., 2004, p.27-28 
- Figura 4 - percentual da categoria que identifica primeiro uma PCR por parte dos sujeitos da pesquisa;

- Tabela 1 e 2 - conhecimento dos sujeitos a respeito da pesquisa.

Após a tabulação dos dados, os mesmos foram apresentados em forma de figuras, tabelas e de forma descritiva.

Buscando o cumprimento dos direitos e deveres relativos á comunidade científica, aos sujeitos da pesquisa e ao Estado frente é Resolução 196/96 do Conselho Nacional de Saúde CNS (BRASIL, 1996), a qual incorpora todas as disposições sobre diretrizes e normas regulamentadoras de pesquisa contendo seres humanos e os quatro princípios básicos da bioética, que são a autonomia, a não maledicência e a justiça. Todos os indivíduos envolvidos foram esclarecidos a respeito dos objetivos da pesquisa, da garantia do seu anonimato, sigilo, respeito, intimidade, privacidade e liberdade de declinar de sua participação no momento que desejar, sendo orientados, quanto à disponibilidade de desistência na participação da pesquisa em qualquer uma de suas fases, sem qualquer prejuízo para a parte desistente.

Vale ainda ressaltar que a pesquisa foi avaliada e aceita pelo Comitê de Ética e Pesquisa da Universidade Estadual da Bahia (CEP/UESB-BA), assim como, a instituição - Hospital Público de Vitória da Conquista/Ba e a população adscrita para a pesquisa (equipe de enfermagem da UTIP), consentiu previamente sua participação através da assinatura do Termo de Consentimento Livre e Esclarecido (TCLE). Foi enviado para o Núcleo de Educação Permanente (NEP), um documento (TCLE) que foi lido e emitido outro que deu plena garantia e validou a realização da pesquisa no HGVC, após assinatura do pessoal responsável pela avaliação e liberação das pesquisas na instituição (coordenadora do NEP).

\section{Resultados e Discussões}

Após elaboração dos questionários estruturados, no mês de Março de 2013, os mesmos, foram entregues para todos os profissionais de enfermagem do serviço da UTI Pediátrica do Hospital geral de Vitória da Conquista/Ba, exceto os pesquisadores para evitar viés na pesquisa; no total da população de 32 funcionários da equipe de enfermagem, somente 25 responderam o questionário, 04 (16\%) enfermeiros e 21 (84\%) técnicos em enfermagem, sendo que, houve resistência por parte de alguns que não responderam as questões, uns devido à falta de tempo e 
outros por estarem de férias e/ou atestado médico, obtendo assim, uma porcentagem de $78 \%$ de respostas da população adscrita.

Foram coletadas as informações relacionadas às técnicas usadas para detecção de uma PCP; quais quesitos são empregados pela enfermagem para examinar a causa/efeito das drogas sobre os pacientes com PCR, analisando assim, tal conhecimento dos profissionais sobre o assunto abordado, como também, a investigação se deu, levando em consideração a periodicidade dos treinamentos em RCP. Ao tabular os dados do questionário aplicado aos vinte e cinco (25) funcionários da equipe de enfermagem, foi necessário fazer menção dos resultados obtidos baseados nos objetivos gerais, específicos e hipóteses levantadas.

A UTIP do Hospital Geral de Vitória da Conquista/Ba, foi fundada no dia 22/12/2003, atuante há 8 anos na região, onde, apenas 4 (16\%) dos funcionários, permanecem no setor em pesquisa por mais de 5 anos, mas a grande maioria totalizando (48\%) da equipe de enfermagem atuam na Unidade de Terapia Intensiva entre 1 e 2 anos, (32\%) tem prestado serviço entre 2 e 5 anos e (4\%) trabalha na UTIP há menos de 1 ano. Este dado nos mostra uma grande rotatividade de funcionários no setor, implicando em uma equipe com pouca vivência e consequentemente podendo apresentar menor prática em situações de urgência e emergência. Este demonstrativo está exposto no gráfico 1 logo abaixo.

Gráfico 1 - Percentual do tempo de serviço dos funcionários que atuam na UTIP do Hospital Público de Vitória da Conquista/Ba, 2011.

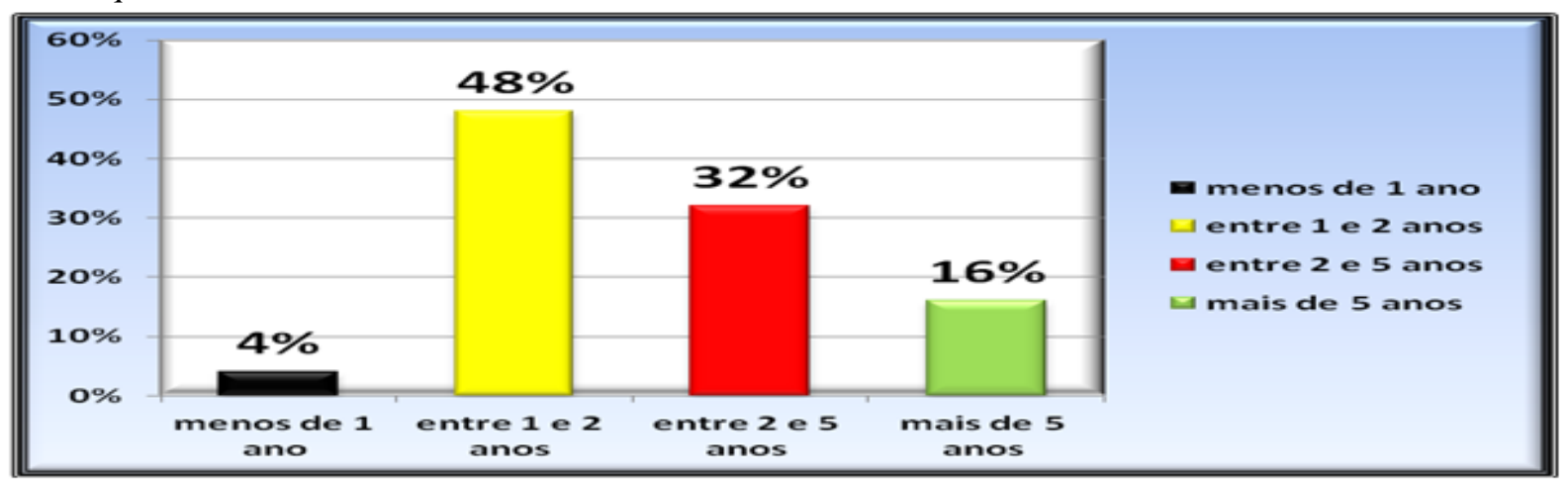

Em relação à faixa etária da população estudada, (48\%) estão entre 25 e 35 anos e outros (48\%) entre 35 e 45 anos, restando apenas (4\%) que estão acima de 45 anos, o gráfico 2, revela que os profissionais de saúde em questão, são adultos jovens, possuindo uma idade ideal para o bom desenvolvimento de suas atividades cotidianas com maturidade e vigor, próprios da 
equipe que se propõe a exercer o cargo dentro de um setor de alta complexidade como este. Desse, 15 (60\%) tiveram aula, curso e/ou treinamento sobre Parada e Reanimação Cardiopulmonar pediátrica no setor ou na instituição em que trabalha, os outros $9(36 \%)$ restante, declara nunca ter recebido aula, curso ou treinamento, ficando 1 (4\%) sem responder a questão.

Gráfico 2 - Percentual da faixa etária dos profissionais de enfermagem da Unidade de Terapia Intensiva Pediátrica do município de Vitória da Conquista, estado da Bahia. Brasil, 2011

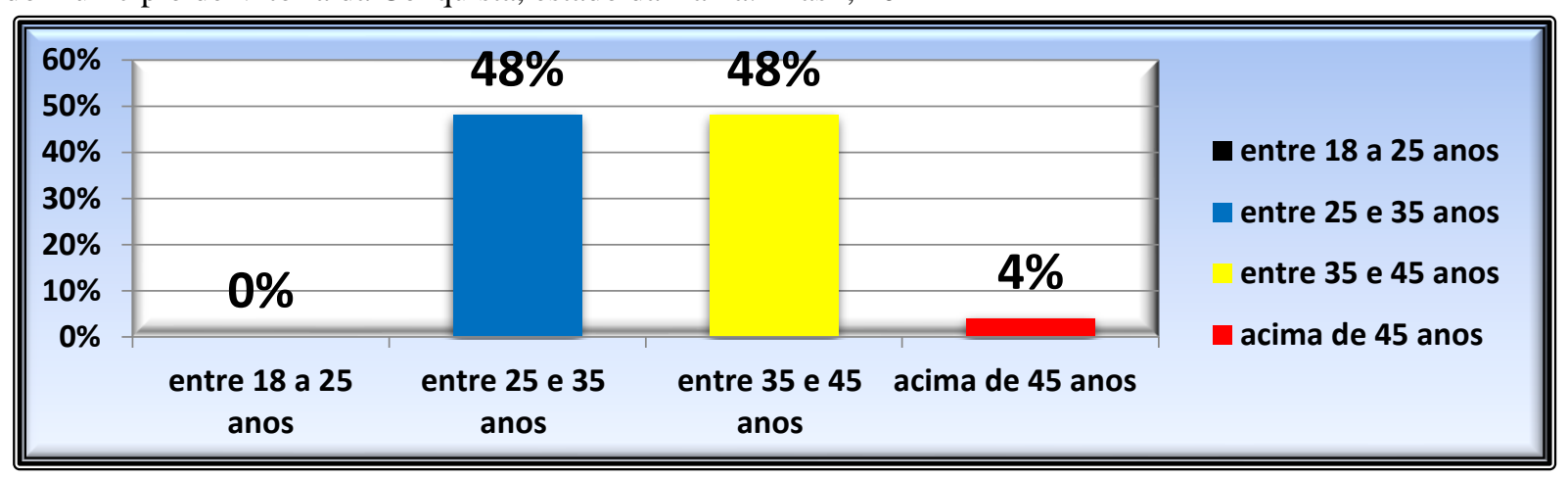

Prosseguindo com a pesquisa e levando em consideração a regulamentação das práticas de RCP, percebe-se que o ideal de treinamento para o profissional que atua em UTI's deveria ser aquele realizado antes de sua admissão no setor e durante sua permanência, intensificado por posteriores treinamentos em exercício (educação continuada). Porém, o gráfico 3 do estudo revela que 4 (16\%) dos profissionais de enfermagem receberam aula, curso e/ou treinamento ao ser admitidos, $1(4 \%)$ receberam ao ser admitido na UTIP e mais uma vez, 3 (12\%) foram treinados ao ser admitido e mais duas vezes após, 2 (8\%) foram treinados ao ser admitido e três ou mais vezes, 5 (20\%) foram treinados após o período de admissão e os 9 restantes (36\%) referem ter aprendido o serviço no cotidiano ao exercer as suas funções, por fim, 1 funcionário (4\%) não respondeu, o que torna o serviço deficitário a respeito da atualização em procedimentos avançados para suprir a necessidade de novas técnicas relacionadas às mudanças que podem ocorrer na própria unidade de trabalho. 
Gráfico 3 - Percentual da frequência de aula, curso e/ou treinamento de Parada e Reanimação Cardiopulmonar recebido pelos funcionários da UTIP de Vitória da Conquista/Ba, 2011.

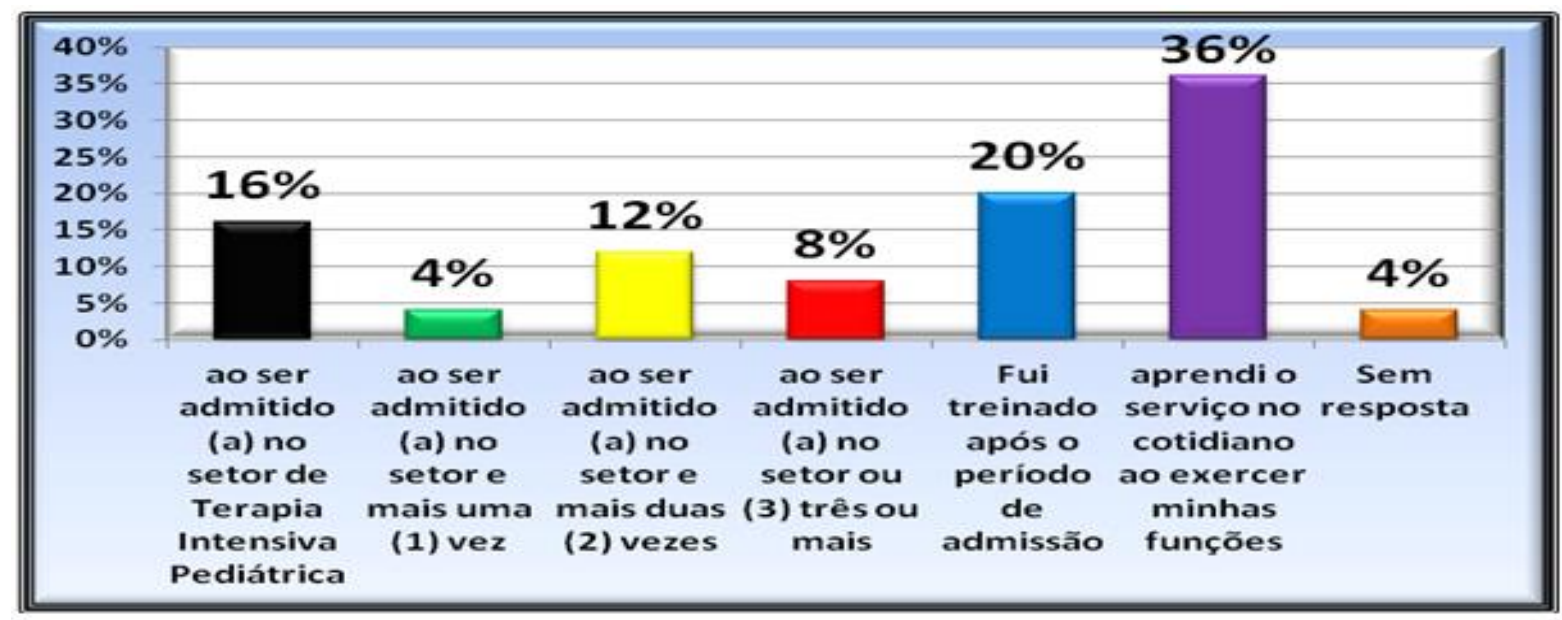

O gráfico acima descreve a quantidade de profissionais que atuam na UTIP sem treinamento específico (36\%), o que seria um grande número, demonstrando assim, uma incapacidade para atuarem neste setor de cuidados avançados e complexos, visto que a UTIP exige habilidades específicas, adquiridas apenas por meio de cursos e treinamentos adequados, pois segundo Laroque (2007), acredita-se que um processo educativo que permita a inclusão permanente de profissionais de saúde no processo ensino-aprendizagem em Ressuscitação Cardiopulmonar e primeiros socorros, vem a ser um caminho viável para a melhoria do atendimento às vítimas, contribuindo assim, para melhores possibilidades de sobrevivência e diminuição das sequelas graves de incapacitação.

A dupla jornada de serviço pode piorar ainda mais as condições estressantes do trabalho (stress ocupacional), a maioria dos profissionais de enfermagem da UTIP desse hospital público afirmaram possuir 2 (72\%) empregos para garantir sua subsistência, ocasionando assim, uma sobrecarga de trabalho e pouca qualidade de vida para os funcionários, podendo levar ao desinteresse funcional.

A grande maioria da equipe de enfermagem reconhece através dos resultados da pesquisa representados logo abaixo no gráfico 4 , que a equipe que primeiro identifica uma Parada Cardiorrespiratória em crianças é a de enfermagem com 96\%, sendo apenas $4 \%$ que afirma ser a equipe médica a perceber primeiro a PCR pediátrica. Isso se dá pela alta proximidade dessa equipe ao paciente hospitalizado, levando o mesmo a perceber com precisão, as intercorrência que envolvem o menor. 
Gráfico 4 - Percentual da categoria que identifica primeiro uma Parada Cardiopulmonar em criança na Unidade de Terapia Intensiva Pediátrica do município de Vitória da Conquista, estado da Bahia. Brasil, 2011

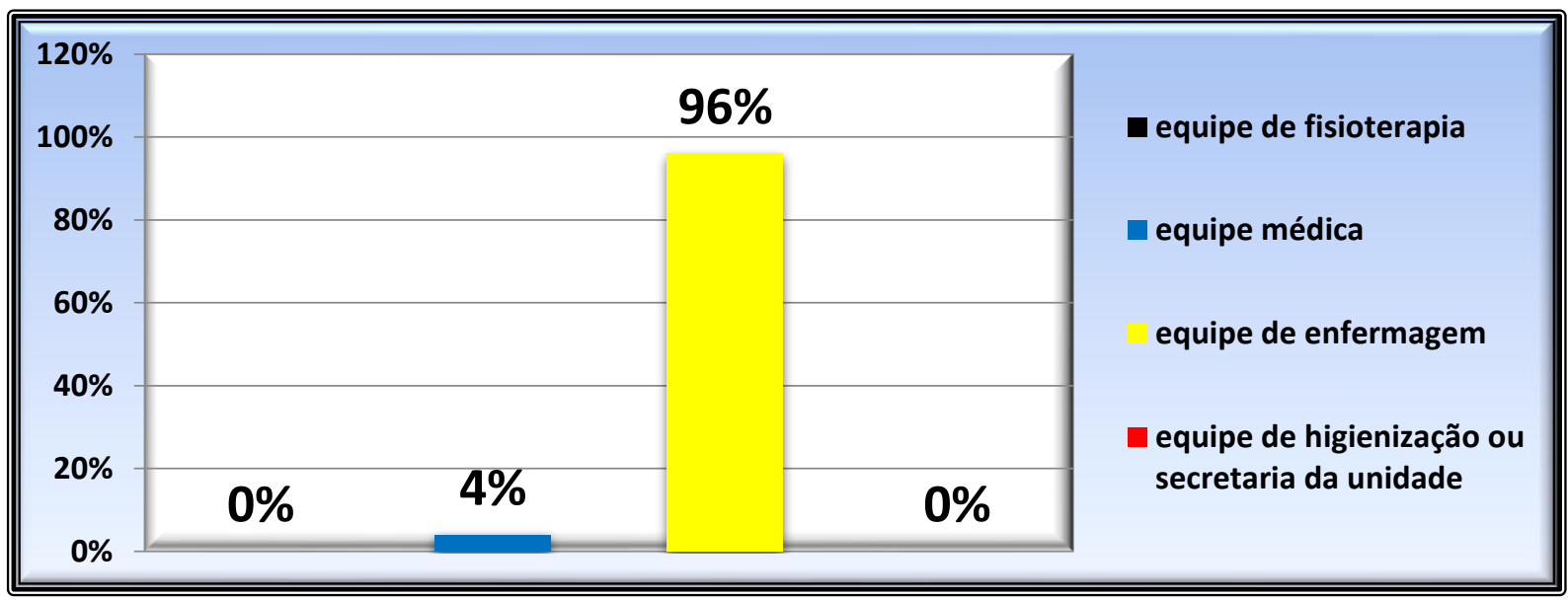

Ao analisar a tabela 1, representada abaixo, observa-se que a equipe de enfermagem acertou mais as questões: $\mathrm{a}-\mathrm{b}-\mathrm{c}-\mathrm{e}$, obtendo na letra $\mathrm{a}-21(84 \%) ; \mathrm{b}-18(72 \%) ; \mathrm{c}-18$ $(72 \%)$; e - 19 (76\%), sendo que as questões, onde, prevaleceram os erros foram as de letra: $\mathrm{d}$ $13(52 \%) ; \mathrm{f}-10(40 \%) ; \mathrm{g}-14(56 \%)$. Se fôssemos acrescentar as pessoas pesquisadas que deixaram de responder por falta de conhecimento, esse total de erros sobe para: $\mathrm{d}-15$ (79\%); f - $16(80 \%) ; g-17(81 \%)$. Demonstraram assim, que a percentagem maior foi de acertos, porém, tiveram dificuldades relacionadas às questões que deram destaque as novas Diretrizes da American Heart Association 2010 para RCP, onde houve algumas mudanças concernentes à prestação de cuidados iminentes na PCR em pediatria.

Tabela 1 - Percentual de acertos e erros da equipe de enfermagem da Unidade de Terapia Intensiva Pediátrica a respeito da Reanimação Cardiopulmonar em criança do município de Vitória da Conquista, estado da Bahia. Brasil, 2011

\begin{tabular}{|c|c|c|c|c|}
\hline \multicolumn{5}{|c|}{$\begin{array}{l}\text { Assinale F (falso) ou V (verdadeiro) e a alternativa que contém a sequencia CORRETA referente à } \\
\text { Reanimação Cardiopulmonar em Criança: }\end{array}$} \\
\hline Questão & Resposta & Acertos & Erros & $\begin{array}{c}\text { Sem } \\
\text { resposta }\end{array}$ \\
\hline $\begin{array}{l}\text { a) Não é necessário uma superfície rígida de apoio para o dorso } \\
\text { da criança, durante a massagem cardíaca. }\end{array}$ & $\mathrm{F}$ & $\begin{array}{c}21 \\
(84 \%)\end{array}$ & $\begin{array}{c}4 \\
(16 \%)\end{array}$ & $\begin{array}{c}0 \\
(0 \%)\end{array}$ \\
\hline
\end{tabular}




\begin{tabular}{|c|c|c|c|c|}
\hline $\begin{array}{l}\text { b) Iniciar a reanimação cardiopulmonar (RCP) em bebês e } \\
\text { crianças com compressões torácicas, em vez das ventilações de } \\
\text { resgate (30 compressões com } 1 \text { profissional) e (15 compressões } \\
\text { com } 2 \text { profissionais), em vez de } 2 \text { ventilações de resgate. }\end{array}$ & $\mathrm{V}$ & $\begin{array}{c}18 \\
(72 \%)\end{array}$ & $\begin{array}{c}5 \\
(20 \%)\end{array}$ & $\begin{array}{c}2 \\
(8 \%)\end{array}$ \\
\hline $\begin{array}{l}\text { c) Para que haja êxito nas compressões torácicas, devem-se } \\
\text { comprimir, aproximadamente, } 1 \frac{1 / 2}{2} \text { polegada }(\text { cerca de } 4 \mathrm{~cm}) \text { na } \\
\text { maioria dos bebês e cerca de } 2 \text { polegadas }(5 \mathrm{~cm}) \text { na maioria das } \\
\text { crianças. }\end{array}$ & V & $\begin{array}{c}18 \\
(72 \%)\end{array}$ & $\begin{array}{c}5 \\
(20 \%)\end{array}$ & $\begin{array}{c}2 \\
(8 \%)\end{array}$ \\
\hline $\begin{array}{l}\text { d) Após a abertura das vias aéreas será necessário o uso do } \\
\text { procedimento "ver, ouvir e sentir se há respiração". }\end{array}$ & $\mathrm{F}$ & $\begin{array}{c}10 \\
(40 \%) \\
\end{array}$ & $\begin{array}{c}13 \\
(52 \%) \\
\end{array}$ & $\begin{array}{c}2 \\
(8 \%) \\
\end{array}$ \\
\hline $\begin{array}{l}\text { e) Em crianças que não respondem e que não apresenta } \\
\text { respiração, se o pulso não puder ser detectado em } 10 \text { segundos, } \\
\text { os profissionais de saúde devem iniciar a reanimação } \\
\text { cardiorrespiratória (RCP). }\end{array}$ & V & $\begin{array}{c}19 \\
(76 \%)\end{array}$ & $\begin{array}{c}4 \\
(16 \%)\end{array}$ & $\begin{array}{c}2 \\
(8 \%)\end{array}$ \\
\hline $\begin{array}{l}\text { f) A carga de energia de desfibrilação inicial em criança deverá } \\
\text { ser de } 2 \mathrm{~J} / \mathrm{Kg} \text {, a segunda carga administrada será de } 4 \mathrm{~J} / \mathrm{Kg} \text {, } \\
\text { podendo exceder pouco mais que } 10 \mathrm{~J} / \mathrm{Kg} \text { nas próximas cargas } \\
\text { para maior êxito no tratamento. }\end{array}$ & $\mathrm{F}$ & $\begin{array}{c}9 \\
(36 \%)\end{array}$ & $\begin{array}{c}10 \\
(40 \%)\end{array}$ & $\begin{array}{c}6 \\
(24 \%)\end{array}$ \\
\hline $\begin{array}{l}\text { g) O índice de sobrevida de pessoas submetidas á reanimação } \\
\text { cardiopulmonar e cerebral, eleva-se acentuadamente, quando o } \\
\text { suporte básico de vida (SBV ou BLS - Basic Life Support), é } \\
\text { iniciado nos primeiros } 3 \text { minutos e o suporte avançado de vida } \\
\text { (SAV ou ACLS - Advanced Cardiac Live Support), em até } 8 \\
\text { minutos, o cérebro começa a sofrer danos e, em 10, a morte } \\
\text { cerebral estar confirmada. }\end{array}$ & V & $\begin{array}{c}8 \\
(32 \%)\end{array}$ & $\begin{array}{c}14 \\
(56 \%)\end{array}$ & $\begin{array}{c}3 \\
(12 \%)\end{array}$ \\
\hline
\end{tabular}

No que diz respeito aos fármacos mais utilizados em crianças na PCR para que haja uma boa reabilitação, foram abordadas na tabela 2 questões relacionadas, para ver o nível de conhecimentos e segurança da equipe sobre causa/efeito, visando uma melhor administração destas medicações. Das 8 questões expostas, a grande maioria dos funcionários do setor em pesquisa, conseguiram acertar 7, mas se levarmos em consideração as pessoas que não responderam, o número de acertos caem para uma média de duas (2) questões, tornando preocupante a quantidade de erros obtido na pesquisa.

Detalhadamente temos, a resposta 2 com 13 (52\%) de acertos, a de número 3 com 13 (52\%) e a de número 5 com $20(80 \%)$ de acertos, totalizando 3 acertos e 5 erros contando com as pessoas que não responderam; são considerados prevalentes erros nas respostas: 1 . Lidocaína 
17 (68\%); 4. Atropina com 13 (52\%); 6. Cálcio 14 (56\%); 7. Epinefrina 15 (60\%); e 8. Bicarbonato de sódio com 15 (60\%) de erros.

Os dados acima revela a atuação mecânica na administração de drogas, baseado no saber empírico dos profissionais de enfermagem que mesmo preocupados com o bem estar da criança, não se aprofundam no conhecimento, muitas vezes por falta de recursos disponíveis, outras por falta de tempo para se dedicar mais a assistência prestada à população infantil. Medicar não se resume em administrar a dosagem certa e/ou fazer um procedimento aleatoriamente, é preciso saber onde levará tal terapia medicamentosa de escolha, é necessário ter conhecimento de causa/efeito no intuito de melhorar o quadro do paciente, por isso, merece a devida atenção e dedicação rumo à satisfação de ver o paciente que passou por uma parada Cardiorrespiratória em perfeito estado físico e psicológico após alta hospitalar.

Tabela 2 - Percentual de acertos e erros da equipe de enfermagem da Unidade de Terapia Intensiva Pediátrica a respeito das medicações mais relevantes para a reabilitação pediátrica, após Parada Cardiopulmonar. Vitória da Conquista-Bahia: 2011.

No momento da parada cardiopulmonar na criança será necessária a administração de medicações relevantes para sua reabilitação. Correlacione as lacunas abaixo as suas respectivas medicações:

\begin{tabular}{|c|c|c|c|}
\hline Questão & Acertos & Erros & $\begin{array}{c}\text { Sem } \\
\text { resposta }\end{array}$ \\
\hline $\begin{array}{l}\text { 1.Lidocaína: bloqueador do canal de sódio que suprime a } \\
\text { arritmia ventricular, pode ser considerada em criança com FV } \\
\text { ou TV sem pulso resistente ao choque elétrico }\end{array}$ & $8(32 \%)$ & $11(44 \%)$ & $6(24 \%)$ \\
\hline $\begin{array}{l}\text { 2.Amiodarona: é um antiarrítmico, efetivo no tratamento de } \\
\text { fibrilação e taquicardia ventricular, tanto em criança como em } \\
\text { adulto }\end{array}$ & $13(52 \%)$ & $8(32 \%)$ & $4(16 \%)$ \\
\hline $\begin{array}{l}\text { 3.Vasopressina: hormônio que atua em receptores } \\
\text { específicos que causam vasoconstrição sistêmica e reabsorção } \\
\text { da água no túbulo renal, aumentando assim, o fluxo sanguíneo } \\
\text { e cerebral }\end{array}$ & $13(52 \%)$ & $8(32 \%)$ & $4(16 \%)$ \\
\hline $\begin{array}{l}\text { 4.Atropina: acelera a condução no nó sinoatrial e } \\
\text { atrioventricular, recomendada no tratamento de bradicardia } \\
\text { sintomática causada por bloqueio AV ou aumento da } \\
\text { atividade vagal como, por exemplo, durante a intubação }\end{array}$ & $12(48 \%)$ & $7(28 \%)$ & $6(24 \%)$ \\
\hline \multirow[t]{2}{*}{ 5.Magnésio: tem ação na hipomagnesemia } & & & \\
\hline & $20(80 \%)$ & $2(8 \%)$ & $3(12 \%)$ \\
\hline \multirow{2}{*}{$\begin{array}{l}\text { 6.Cálcio: preconizado quando houver } \begin{array}{c}\text { suspeita ou } \\
\text { comprovação de hiperpotassemia, hipocalcemia, } \\
\text { hipermagnesemia e superdosagem de canais de cálcio }\end{array} \\
\end{array}$} & $11(44 \%)$ & $8(32 \%)$ & $6(24 \%)$ \\
\hline & $10(40 \%)$ & $9(36 \%)$ & $6(24 \%)$ \\
\hline
\end{tabular}




\begin{tabular}{|c|c|c|c|}
\hline $\begin{array}{l}\text { 7.Epinefrina: catecolamina endógena com ação estimulante } \\
\text { nos receptores } \alpha \text { e } \beta \text {, sendo que a } \alpha \text { é mais importante durante } \\
\text { a parada cardiopulmonar por causar vasoconstrição e } \\
\text { restaurar a pressão diastólica na aorta, proporcionando assim } \\
\text { melhor perfusão miocárdica e cerebral }\end{array}$ & & & \\
\hline $\begin{array}{l}\text { 8.Bicarbonato de sódio: após a PCR, onde a criança estará } \\
\text { com ventilação assistida, suplementação de oxigênio e } \\
\text { restauração da perfusão por meio das compressões torácicas e } \\
\text { do uso da epinefrina, essa medicação pode ter efeito na PCR } \\
\text { prolongada (mais de } 10 \text { minutos) em crianças que já tinham } \\
\text { acidose metabólica previamente. Sua indicação será mediante } \\
\text { a comprovação na parada cardíaca de hiperpotassemia, } \\
\text { hipermagnesemia e intoxicação por antidepressivos tricíclicos } \\
\text { e outros bloqueadores de canais de sódio }\end{array}$ & $10(40 \%)$ & $9(36 \%)$ & $6(24 \%)$ \\
\hline
\end{tabular}

\section{Considerações Finais}

Sabe-se que, das crianças que tiveram uma Parada Cardíaca em ambiente hospitalar, apenas 15-20\% estarão vivas em um ano depois do evento, desses sobreviventes, a maioria apresentará sequelas significativas. Esses dados fazem com que os profissionais sejam mais receosos e tentem identificar primeiro os pacientes sob risco de Parada Cardíaca para intervir precocemente. Essa preocupação direcionou a pesquisa para analisar a conduta de enfermagem (técnicos e enfermeiros), frente a uma Parada Cardiorrespiratória em criança na Unidade de Terapia Intensiva Pediátrica (UTIP) do Hospital Geral de Vitória da Conquista/Ba (HGVC), impulsionando assim, o delineamento do tema: Parada e Reanimação Cardiopulmonar em criança: atuação da equipe de enfermagem da Unidade de Terapia Intensiva Pediátrica de um hospital público de Vitória da Conquista/Ba.

No tratamento dos dados, traçou-se o perfil da equipe de enfermagem da UTIP do HGVC, onde dos 25 funcionários entrevistados a maioria são técnicos em enfermagem com faixa etária entre 25 e 45 anos.

Ao abordar sobre a participação dos sujeitos da pesquisa em aula, curso e/ou treinamento em Parada e RCP em crianças, foi notório que, grande parte fez em algum momento o treinamento no setor ou instituição referida, porém, dentre esses, a maioria (20\%) foram treinados após admissão na unidade e outros (36\%) não receberam treinamentos, tendo que aprender o serviço no cotidiano ao exercer suas funções, mesmo assim, afirmaram ser a equipe 
de enfermagem quem primeiro identifica uma Parada Cardiorrespiratória em criança, isso, devido a grande proximidade dos mesmos com os pacientes.

Ao analisar o conhecimento técnico-científico, percebe-se que, demonstraram uma maior segurança nas respostas das questões baseados nas Diretrizes de AHA 2005, mostrando desconhecimento quando eram abordadas as novas Diretrizes da AHA de 2010.

Apesar de não haver nenhuma mudança nas Diretrizes da AHA de 2010 em relação às drogas mais relevantes na Parada Cardiopulmonar, os profissionais de enfermagem ao externar seu conhecimento, demonstraram um maior percentual de erros nestas questões, indicando ser este, um ponto relevante a ser trabalhado com a equipe, direcionando a causa/efeito das drogas no organismo da criança a Parada Cardiorrespiratória.

\section{Referências}

SPAPE, Alberto et al. Manual de normas: terapia intensiva pediátrica. 2. Ed. - São Paulo: Sarvier, 2009.

AMERICAN HEART ASSOCIATION. Destaque das Novas Diretrizes de RCP e ACE. [internet]. 2010. Disponível em:

<http://www.hu.ufsc.br/uti/docs/Guidelines\%20AHA\%202010.pdf>. Acesso em: 31/01/2013.

\section{AMERICAN HEART ASSOCIATION. Diretrizes da American Heart Association [internet]. 2005 [acessado em 29 de Jan. 2013]. Disponível em: $<$ http://www.ebah.com.br/content/ABAAABW7YAB/diretrizes-american-heart-association- 2005> Acesso em: 29/01//2013.}

BRASIL, MINISTÉRIO DA SAÚDE. RESOLUÇÃO 196/96 DO Conselho Nacional de Saúde/MS: Sobre diretrizes e normas regulamentadoras de pesquisa envolvendo seres humanos. Diário Oficial da União, 10 de outubro de 1996.

FIGUEIREDO, N. M. A. de; SILVA, C. R. L. da; SILVA, R. C. L. da. Unidade de Terapia Intensiva-UTI. In: Coord. CTI: atuação, intervenção e cuidados de enfermagem. 2. ed. ver. atual. São Caetano do Sul, São Paulo: Yendis Editora, 2009.

GRASSIA, R. de C. F. O enfermeiro e as situações de emergências. São Paulo: Atheneu, 2007.

KROSGER, M. M. A. et al. Enfermagem em Terapia Intensiva: do ambiente da unidade á assistência ao paciente. 1. ed. São Paulo: Martinari, 2010. 
LAROQUE, M. F.; AFFELDT, A. B.; NEVES, C. R. C.; VAUCHER, M. O.; LANGE, C. Capacitação em reanimação Cardiopulmonar. Universidade Federal de Pelotas, 2007. Disponível em: <http://www.abev.com.br/emergencia/posteres/id73.pdf>. Acesso em: 31/01/2013.

OLIVEIRA, R. G. de. Blackbook-Pediatria. 3. ed. Belo Horizonte: Bleck Book Editora, 2005.

PAVELQUEIRES, S. et al. Manobras Avançada de Suporte ao Trauma e Emergências Cardiovasculares. 6. Ed. Marília-São Paulo: Manual do curso MAST, 2006.

POLIT, D. F.; BECK, C. T.; HUNGLER, B. P. Fundamentos de pesquisa em enfermagem: métodos, avaliação e utilização. 5. ed. Porto Alegre: Artmed, 2004.

SMELTZER, S. C.; BARE, B. G. (trads) Brunner e Suddarth: Tratado de Enfermagem Médico-cirúrgica. 10. ed. Rio de Janeiro Guanabara Koogan, 2005.

STAPE, A. et al. Avaliação Inicial. In: Coord. Manual de normas: terapia intensiva pediátrica. 2. Ed. São Paulo: Sarvier, 2009.

STOPFKUCHEN, H. Emergências Pediátricas. Tradução Rinaldo Koester Santoni. 1. ed. São Paulo: Rideel, 2010.

TANNURE, M. C.; PINHEIRO, A. M. SAE: Sistematização da Assistência em Enfermagem. 2. ed. Rio de Janeiro: Guanabara Koogan, 2010.

\section{Como citar este artigo (Formato ABNT):}

SANTOS, Elenito B. Parada e Reanimação Cardiopulmonar em Criança: atuação da equipe de enfermagem da Unidade de Terapia Intensiva Pediátrica em hospital público de Vitória da Conquista Bahia. Id on Line Revista ultidisciplinar e de Psicologia, 2017, vol.12, n.39, p.410-431. ISSN: 19811179.

Recebido: 15.12 .2017

Aceito: 18.12 .2017 